https://doi.org/10.48009/1_iis_2009_232-236

\title{
THE SKILL SETS FOR GEOGRAPHIC INFORMATION SYSTEM FOCUS: COMPETITIVE INTELLIENCE IN THE INFORMATION SYSTEMS CURRICULUM
}

\author{
Peter Y. Wu, Robert Morris University, wu@rmu.edu \\ Frederick G. Kohun, Robert Morris University, kohun@ rmu.edu
}

\begin{abstract}
Geographic Information System (GIS) is becoming more and more widely used in many different areas of application, but the workforce skilled in the technology is still in short supply. GIS courses to provide the needed training are becoming available at various levels in colleges and universities. We share our experience in the design and development of new GIS courses, including a brief survey of the equipment and sources of data needed to launch a GIS course. We then analyze the course syllabus design to focus on the skill sets needed to meet the demands of the going trends in the IS/IT market place. The skill sets include: (1) skills in data and files manipulation, (2) spatial analysis and statistical reasoning, and (3) graphic arts design in map presentation. We also discuss the on-going development of GIS technology, and how the IS curriculum may plan to prepare students for these future trends.
\end{abstract}

Keywords: GIS, Geographic Information Systems, Competitive Intelligence, IS Curriculum.

\section{INTRODUCTION}

The use of Geographic Information Systems (GIS) has been growing tremendously in many areas of application. From the traditional application areas of land use and logistics planning, we now find GIS in use for demographics analysis in marketing as well as political campaigning, and simple route finding with maps on the internet, or with GPS (global positioning system) used in a car. The reason for the proliferation is two fold: on the one hand, it is the continued lowering of hardware and software cost for the user, and on the other hand, the ease of access to useful data on the internet.

In 2004, the Department of Labor has identified geospatial technology as one of the top three fastest growing industries in the United States, behind nanotechnology and biotechnology, and estimated the annual market revenue to be US $\$ 30$ billion by 2005 . (Gewin 2004) Geospatial technology has since stayed in the Labor Department's High Growth Industry Profile every year, with market growth at the annual rate near $35 \%$. The public sector had two third of the market in 2004, but the commercial subsection of the market has been growing annually at $100 \%$. Yet, the Labor Department continues to cite the severe shortage of workforce skilled in GIS and related technologies. (DOL 2009).

In the past five to ten years, many GIS courses and programs have been springing up not only in institutions of higher education and professional training, but also in K-12 schools (Glover 2005) and in distance learning (Wen 2007). Among the universities, there are also varieties of GIS offering, depending on the disciplinary area of the school. GIS courses found in schools of business, public policy studies, environmental planning, geographical science, health care and disease control, as well as information systems.

In this paper, we share our design of GIS course in our IS curriculum, but we also analyze the design in how it focuses on the few skill sets to emphasize the value of its application. GIS is a multi-disciplinary area of study. Our intention is to draw the course design to an appropriate focus. We will also briefly discuss the future trends of GIS technology, to anticipate the necessary on-going additions and changes.

\section{GIS COURSE OUTLINE}

Since 2005, we have added two GIS courses in our IS curriculum, one at the undergraduate level and the other at the graduate level, both as advanced electives in the current IS programs. The undergraduate course "Introduction to GIS" provides the students an overview of GIS and its use. The course introduces GIS from its roots in computer cartography and covers the issues of map representation, including data and file structures. Building on an understanding of the architectural model, the students will get a glimpse of the wide range of GIS applications. The graduate course "GIS: Tutorial and Applications" develops the architectural model of understanding GIS through tutorials, and followed by the applications of spatial analysis. In both cases, students will acquire hands-on experience in projects using GIS on a personal computer. The authors 
presented the scope of the two courses in details in an earlier paper ( $\mathrm{Wu}$ and Kohun 2005). The following sums up the scope by outlining the topics covered in the GIS course.

Topic 1. Introduction to GIS

- GIS and the map layers, zooming and panning

- Identify, search, label map features

- Vector and raster maps: data structures

- Coordinate system: projection, reference, datum

- Map scales and measurements

Topic 2. File Formats and Geo-databases

- GIS data model: geometry, topology, and data

- Data structure and file formats

- Query interface: search by attribute by location

- Import and Export of attribute data

- Data acquisition and digitizing

Topic 3. Fundamentals of Map Design

- Reference mapping and analytic mapping

- Points, lines, polygons and choropleth maps

- Types of maps and the intended audience

- Map layout and presentation design principles

- Statistics and visual techniques

Topic 4. GIS Processes: Inputs and Outputs

- GIS resources on the internet

- Join operations in geo-databases

- Proximity analysis and planning

- Map overlay and spatial analysis

- Network and topology analysis and logistics

- Geo-coding and address mapping

Topic 5. Spatial Data Processing and Analysis

- Problem solving using map features

- Decision support with GIS

- GIS project

The primary value of the GIS courses is in the applications. That is appropriate for GIS courses in the IS curriculum. Yet a conceptual understanding of the basic GIS architecture is still fundamental in the intelligent use of GIS in its application. Particularly with the variety of data formats, the technology is still in its infancy. A reasonable level of maturity in understanding the technical system aspects of GIS is quite essential. More, the outline above clearly shows the inter-disciplinary nature of GIS skills, involved with the computer information system, the expert GIS user also needs to be trained in statistics, graphic art design, as well as cartography. Yet most certainly, the topics and the sub-topics as listed do not all carry equal weight. We will be discussing the appropriate focus for the effective skill sets in a later section.

\section{LAB EQUIPMENT AND DATA SOURCES}

Traditionally, use of GIS is a very costly proposition because of the expensive equipment needed to support GIS. However, in he past several decades, not only the cost of hardware and software has gone down substantially, but the advances of computer technology also obviated the use of many peripherals. Granted the capabilities of personal computers today, most schools offering an IS program may already run a laboratory with a local area network of computers with internet access and reasonable performance. Much of the traditionally needed equipment is no longer necessary.

First, there is now no need for a large flat-bed plotter. Normally there is no need to print out a large map on paper. Even for occasional use, local print shops (such as Kinko) will provide the service for a small charge. Second, there is now no need for digitizers. To import data from a printed map or an aerial photo, we can display the scanned digital image (map or photo) in the background. The GIS as well as many available tools today allow us to use the mouse to interactively indicate points on the screen to import coordinates as map data (Clarke 2003, p.205). The interactive graphical use of mouse and screen functionally obviates the flat-bed digitizer. A good scanner can be useful, as much as a color printer. Yet again, both of these can be shared with other shops or labs for its occasional use.

We should be concerned about the appropriate screen size, and the amount of memory and disk storage on the computers. 17" screen should be sufficient for most general use, while 15 " screen may be a bit small and somewhat inconvenient. Yet these screen sizes are indeed compatible with IS computer labs today. For common GIS software, the smaller screen does not prohibit its use. The memory storage requirement is dependent on the specific choice of GIS software. Most applications on the Windows XP platform need 256M memory. Common GIS software runs with reasonable performance in that configuration. Large map data files are buffered in disk storage. Disk storage is quite inexpensive now, and is usually provided by a server via the local area network. Our practice allocates $10 \mathrm{M}$ quota for each student and that is quite sufficient. Students bring in their flash drive sticks to carry the map and data files with them.

The critical element is the GIS software license. There are two leading GIS software vendors: ESRI and Manifold. ESRI has the major portion of the market share and can run on various platforms, while Manifold runs only on the Windows Server platform. 
The following lists their websites and their current prices for a configuration common for academic use.

\section{ArcGIS from ESRI}

Environmental Science Research Institute, Inc.

Website: $w$ ww.esri.com

GIS Software: ArcView (common ArcGIS version)

Price: $\$ 1750$ per 25 seats floating license.

Maintenance: $\$ 300$ per year for subsequent years

(Purchase price includes first year maintenance and technical support.)

\section{Manifold .Net System}

Manifold Net Ltd, Inc.

Website: $w w w$. manifold.net

GIS Software: Manifold .Net

Price: \$230 per seat for $10-49$ seats at 30\% discount.

Maintenance: none.

(Floating license will need the purchase of license server, which is separately priced.)

The US government provides a great deal of maps and other data for GIS use. These are often publicly available on the internet. The data is good enough for student projects. Timely data of commercial value often can be purchased. The following table lists some of these organizations and their websites with much useful data freely available for public use:

\begin{tabular}{|l|}
\hline Environmental Protection Score Card \\
www.ScoreCard.org \\
\hline Environmental Science Research Institute \\
www.esri.com \\
\hline University Consortium for Geographic Info Science \\
www.ucgis.org \\
\hline US Census Bureau \\
www.census.gov \\
\hline US Geological Survey \\
www.usgs.gov \\
\hline US Hometown Locator \\
www.hometownlocator.com \\
\hline
\end{tabular}

The above is but a partial list. An introductory GIS textbook such as (Clark 2003) would provide a much more comprehensive list and elaborate details about each of the sources.

\section{FOCUS ON ESSENTIAL SKILL SETS}

The value of GIS courses in the IS curriculum is in the applications. However, the skillful use of GIS in its application needs to be built on the basic concepts of the information system, and the familiarity of the tools in use. Our course design intends to build on a fundamental conceptual model of GIS architecture so that we may understand the functionalities well. We identified the following skill sets covered in the topics. In the following, we discuss each of these skill sets in further details.

\section{Basic IS Concepts and IT Skills}

GIS is a tool for geospatial data handing, with a very interesting graphical user interface. The basic IS concepts for using GIS include that of database systems, more specifically use of SQL in a relational database system. But the data involved may also be spatially related. We can present the data visually, in a map. Students also need to understand the use of map layers and how they are presented visually like that on a light table. But more important is the integration of relational data into the geometry and topology of the map. Therefore, students need to first understand the difference between vector maps and raster maps, and how vector maps in the GIS allow for the integration of map and data in the system.

\section{Geography and Mapping Skills}

Each map layer has its reference coordinate system. Geographical coordinates of latitude and longitude are projected on the 2D map. Students need to understand the concept of projection. But for GIS in the IS curriculum, we would contend that it is not necessary to dig deep into the various details of different projections. For most community mapping applications using GIS, it is not necessary for students to get too involved as long as they understand the different reference coordinate system in use for different data sources.

\section{Statiscal/Math Reasoning and Presentation}

This is the primary core skill set in GIS application. Students need to be well prepared to be able to do well in a GIS project, in the use of spatial analysis. Careful interpretation of data presented is quite necessary when using GIS to analyze and present spatial data. GIS course should focus heavily on the use of spatial and network analysis, in overlay and proximity studies. This is also where intelligent use of information may emerge when the GIS user's skill level matures.

\section{Graphic Arts Design Principles}

Since presentation of spatial data is done in a map, often using color. The graphic arts design principles in using colors are fundamental to the skills of map design. The design of choropleth map is an important fundamental skill, involved with the choice of color variations and the corresponding data range intervals. Students taking GIS courses in the IS curriculum may or may not be prepared for this. Some introductory coverage of graphic arts design principles will go a long way for the students in their design of maps and 
how to present the data graphically to support an argument.

\section{Geo-coding and Address Matching}

Geo-coding is the processed of interpreting coded information into location information. A common example is in converting a street address into a location in a map. In order to deal with the many ways human information is coded - such as the many ways a street address is written, the geo-coding tool in the GIS is often like an expert system tool. It actually does not require much geography knowledge to operate, but rather an understanding of how expert systems may be configured. Address matching is a common task in community mapping applications. For students in the IS curriculum, geo-coding is an indispensable skill for GIS use.

\section{FUTURE TRENDS OF GIS TECHNOLOGY}

Traditionally we make maps for reference, that is, to look up things. With the tremendous versatility of GIS, we also conveniently make maps for the purpose of analysis. When our purpose is to reason about what is happening, we process the data for investigation to make maps which illustrate the evidence to support our argument for our decision.

When GIS does map rendering on the computer, we can further take advantage of the interactive use of computer graphics. The user may directly interact with the GIS by adjusting rendering parameters through the use of interactive gadgets. Figure $\mathrm{X}$ illustrates a map to highlight the census blocks with average annual income higher than a certain amount. The GIS refreshes the map as needed while the user makes adjustment of the dollar amount on a slider. The approach allows the user to gain a visual perception of how the parametric value under control relates to the spatial distribution, such as the range of income level in the neighborhood. It would be very valuable in political campaigning to comprehend the range of party membership, or in public health administration to understand the spread of an epidemic in a community (Scotch et al 2006). Dynamic map rendering as described above is still new and is not yet readily available in most GIS's unless the system is extended by programming support (Gervais 2005).

Even when GIS is becoming less and less inexpensive, latest research in system design is increasingly trying to provide GIS functionality on the web. This means that the users of GIS do not need to have the GIS software installed on a local computer, but as long as there is reasonable internet connectivity, GIS functions are available on the web through the use of a web browser. It is called the web-based GIS (Peng and Tsou 2003).

As a web-based application, GIS will become even more accessible. Quite often government agencies use a web-based GIS to provide GIS functions to the public for access to their maps and data. Vender software systems for web-based GIS are available: prevailing ones, for example, include ArcGIS Server from Environmental Science Research Institute (ESRI 2006) and Manifold Internet Mapping System (CDAI 2008), following from behind. More specialized GIS functions are often not available in these systems via the web. Research in system design and development of web-based GIS functions is on-going (Calder 2008), and GIS will be even more commonly available to the public.

\section{SUMMARY}

While the use of GIS is proliferating in many areas of application, and the market is growing fast, the clear limitation is the short supply of skilled workforce in the area of GIS technology. At the same time the IS/IT market is seeking a competitive advantage in the intelligent use of information, GIS emerges as a viable tool for analytic mapping and decision support - a tool for competitive intelligence. Varieties of GIS courses emerge. We shared in this paper the approach to our design of the GIS courses in the IS curriculum. We also shared our brief survey of the equipment and data sources to support the GIS lab. We went on to analyze the scope of topics coverage, identifying five specific skill sets. We discuss each of these skill sets to draw attention to the appropriate focus for GIS courses in the IS curriculum. Our aim is to amplify the primary value of the GIS course - that is, the value of its application, in the IS curriculum. By briefly discussing the future trends of GIS, we also investigate how we may want to expand the focus skill sets in the future.

\section{REFERENCES}

Boasson, E., V. Boasson and W.J. Tastle (2004) “A New Tool in IS Management: Geographic Information Systems." Proceedings of ISECON 2004 v.21, Newport, RI, §.3124.

Calder, I., J. Garratt, P. James and E. Nash (2007), Models, Myths and Maps: Development of the Exploratory Climate Land Assessment and Impact Management (EXCLAIM) Tool, Environmental Modelling and Software, Vol.23, No.5, May 2008, pp.650-659. 
Caputo, Kovacs, and Turchek (2004). Defining the Essential Skill and Functional Areas of Study in IT as Measured by a Survey of Field Professionals. Proceedings of ISECON 2004, Newport, RI., v.21, SS.2215, October 2004.

CDA International Ltd. (CDAI 2008). Manifold Internet Mapping System Manual, complete manual, 2008.

Clarke, K.C. (2003) Getting Started with Geographic Information Systems, $4^{\text {th }}$ edtion, Prentice Hall.

Environmental Science Research Institute (ESRI 2006). ArcGIS Server: ESRI's Complete Server GIS, An ESRI white paper, December 2006.

Gervais, E., D. Nussbaum, J-R. Sack (2005), DynaMap: a Context Aware Dynamic Map Application, Proceedings of GIS Planet 2005 Conference, Estoril, Portugal, June 2005.

Gewin, V. (2004) Mapping Opportunities. Nature, Vol.427, pp.376-377.

Glover, B. (2005), "Curriculum Update for GIS Programs in Texas Community Colleges," $5^{\text {th }}$ Annual ESRI Education User Conference, July 2005, San Diego, CA.

Gorr, W.L., K.S. Kurland. (2007), Learning and Using Geographic Information Systems, Thomason Course Technology.

Mitchell, A. (1999) The ESRI Guide to GIS Analysis Vol.1: Geographic Patterns and Relationships, ESRI Press, Redlands, CA.

O’Looney, J. (2000) Beyond Maps: GIS Decision Making in Local Government, ESRI Press, Redlands, CA.

Peng, Z.R. and M.H. Tsou. (2003) "Internet GIS." John Wiley and Sons, Inc.
Reames, S. (2005) "Business Geographic Information Systems - A Course in Business Geomapping," Proceedings of ISECON 2005 v.22 (Columbus OH): $§ 2334$.

Scotch, M., B. Parmanto, C.S. Gadd and R.K. Sharma (2006), Exploring the Role of GIS during Community Health Assessment Problem Solving: experiences of public health professionals, International Journal of Health Geographics 2006, Vol.5, No.39.

Sinton, D.S. and J.L. Lund. (2007) Understanding Place: GIS and Mapping Across the Curriculum, ESRI Press, Redlands, CA.

US Department of Labor. (2009) Employment and Training Administration, High Growth Industry Profile - Geospatial Technology.

[http://www.doleta.gov/brG/Indprof/geospatial_p rofile.cfm]

Wen, T.S. and H.C. Lin. (2007) "The Study of ELearning for Geographic Information Curriculum in Higher Education," Proceedings of $6^{\text {th }}$ International Conference on Applied Computer Science, Hangzhou, China, published by World Scientific and Engineering Academy and Society, Vol.6, pp.626-621.

Wu, P.Y. and F.G. Kohun. (2005) "Designing Geographic Information System Courses in the IS Curriculum," Proceedings of ISECON 2005 v.22 (Columbus OH): § 2564.

Wu, P.Y. (2007) "Introducing Geographic Information Systems into the IS Curriculum: GIS Tutorial and Preparation Workshop," Proceedings of ISECON 2007 v.24 (Pittsburgh PA): §3732. 